\title{
Willingness to Pay for Green Products in Air Travel: Ready for Take-Off?
}

\author{
Gieri Hinnen, ${ }^{1 *}$ Stefanie Lena Hille ${ }^{1}$ and Andreas Wittmer ${ }^{2}$ \\ ${ }^{1}$ Institute for Economy and the Environment, University of St. Gallen, St. Gallen, Switzerland \\ ${ }^{2}$ Center for Aviation Competence, University of St. Gallen, St. Gallen, Switzerland
}

\begin{abstract}
We examine the willingness to pay (WTP) for green products in air travel. Green products in aviation are supplementary services, which are sold on top of the travel service (e.g. carbon offsets, organic on-board food). We identify a set of potential green products in aviation and report the preferences for additional airline services of 811 Swiss air travellers using an adaptive choice-based conjoint survey. We find that $20 \%$ of those passengers who are interested in purchasing supplementary services show a considerable WTP for green products. The green segment differs from the regular segment only in terms of behavioural features, not in terms of demographic or socio-economic characteristics. Copyright (c) 2015 John Wiley \& Sons, Ltd and ERP Environment
\end{abstract}

Received 13 January 2015; revised 18 August 2015; accepted 28 August 2015

Keywords: sustainable transport; green product; conjoint; aviation

\section{Introduction}

A

IR TRAFFIC'S SHARE OF GLOBAL CARBON EMISSIONS AMOUNTS TO $2 \%$, BUT ITS EMISSIONS ARE EXPECTED TO CONTINUE growing at 3-4\% per year (Metz et al., 2007). Passengers have become increasingly aware of the effects of air traffic on the environment (Wegelin and Wittmer, 20I3). However, are air travellers willing to pay a premium for 'green products' in aviation?

In recent years, airlines have started to offer green products on top of the standard airfare (Wittmer and Rowley, 20I4), such as voluntary carbon offsetting or organic on-board food. It is assumed that a segment of passengers, the 'green niche', has a considerable willingness to pay (WTP) for green products, as is the case in other industries (Ottman et al., 2006). However, little is known about the demand for green products in aviation (McLennan et al., 2014; Van Birgelen et al., 20II).

This paper aims to fill this knowledge gap. We explore the WTP for green products in air travel, specifically analysing what constitutes the green segment. We conduct an adaptive choice-based conjoint analysis with air travellers in Switzerland. We find that $20 \%$ of those passengers who are interested in purchasing supplementary services have a strong preference for green airline services ('green segment'). Interestingly, the 'green segment' does not differ with regards to demographic criteria from the 'regular segment', but only in terms of behavioural criteria. We contribute to research on green products, in particular aspects of segmentation (Diaz-Rainey and Ashton, 20II;

*Correspondence to: Gieri Hinnen, Institute for Economy and the Environment, University of St. Gallen, St. Gallen, Switzerland. E-mail: gieri. hinnen@unisg.ch 
Mair, 20II; Tabi et al., 20I4; Thompson et al., 20I0), as well as to the discussion on sustainable transport (Font et al., 2008; Oberhofer and Fürst, 20I3; Vespermann and Wittmer, 20II).

\section{Background and Hypotheses}

Green products encompass a range of categories in aviation, such as carbon offsets or organic on-board food. From an environmental point of view, the first-best solution would be to integrate such green products directly into the standard airfare. However, aviation is characterized by intense competition and highly price-sensitive consumers (Brons et al., 2002). As a result, airlines increasingly 'unbundle' their products in order to let '...customers select and pay for only those services they desire' (Berman, 20I5, p. 94). Airlines progressively offer a standard airfare that only includes the flight. Passengers have the opportunity to purchase 'supplementary services' depending on individual needs (Wittmer and Rowley, 20I4). This includes services such as checked baggage or upgraded meals (Sorensen and Lucas, 20I4). Similarly, green products commonly also take the form of 'supplementary services' (Wittmer and Rowley, 20I4).

Research shows that environmentally preferable features of products have an impact on customers' choices, intentions and WTP (De Pelsmacker et al., 2005; Hampl and Loock, 2013; Kaenzig et al., 2013). Existing research on demand for green products $\mathrm{n}$ air travel almost exclusively focuses on carbon offsets, with mixed results. Using a survey method, McLennan et al. (20I4) find that only 2-3\% of travellers in Australia are willing to purchase carbon offsets. Mair (20II), also based on survey data, reports that I0\% of her sample has previously purchased carbon offsets. Blasch and Farsi (2013), drawing on the results of a choice experiment in Switzerland, report that 25\% of respondents show a high propensity and a high WTP for offsets, whereas I7\% are interested in offsets, but only at low cost. The sparse research suggests that there is a segment that displays a considerable WTP for green products in air travel. This is in line with research outside of the aviation context, which suggests that WTP for green products differs widely across segments (see for instance Tabi et al., 20I4). We expect that a 'green segment' also exists in aviation. This leads us to the following hypothesis.

HI: A 'green segment' in aviation exists that displays a significantly higher overall stated WTP for green products in air travel relative to the 'regular segment'.

Research indicates that the demand for a green product is dependent on its co-benefits. Ottman et al. (2006) postulate that customers outside the 'green niche' are not satisfied with a product just 'being green', but demand additional value in terms of lower costs, health and safety benefits, better performance, greater convenience and symbolism and status. For instance, organic on-board food is chemical free and thus has a positive impact on health. Similarly, a green travel pack, which is distributed on board, has an effect in terms of symbolism and status (Griskevicius et al., 20I0). An example of a 'pure' green product is carbon offsetting or green ground transport. Such products or services have low carbon emissions, but do not provide any co-benefits such as lower costs or health or safety benefits (Ottman et al., 2006). Consequently, we suggest the following hypothesis.

H2: The 'regular segment' displays a higher stated WTP for green supplementary products that provide additional benefits in terms of symbolism and health than for supplementary green products that do not offer such co-benefits.

A key question is how the 'green segment' can be distinguished from the regular segment. With regards to socioeconomic and demographic factors, the evidence is mixed. Fisher et al. (20I2) report that only gender and income have a significant impact on environmental purchasing behaviour: women are more prone to purchase environmentally friendly products, as are individuals with a comparably high income. With respect to air travel, existing research on green products focuses exclusively on carbon offsetting. Mair's (2OII) findings indicate that customers of carbon offsets in air travel 'were more likely to be male, younger and on average with slightly higher education levels' (p. 223). In contrast, Choi and Ritchie (2OI4) find that socio-demographic criteria do not explain differences in the WTP for carbon offsets. These findings may be linked to research on the adoption of 'green energy', as this has 


\section{Willingness to Pay for Green Products in Air Travel}

similar characteristics to carbon offsetting. Both are so-called 'pure' green products that do not deliver additional cobenefits (Ottman et al., 2006). Gerpott and Mahmudova (2010) show that younger consumers display a higher WTP for green electricity. Several studies conclude that income, household size and education positively correlate with the WTP for green electricity (Diaz-Rainey and Ashton, 20II; Ek and Söderholm, 2008). This yields the following hypothesis.

$\mathrm{H}_{3}$ : The 'green segment' in air travel is more likely (a) to be male, (b) to be younger, (c) to be better educated, (d) to live in larger households, and (e) to have higher incomes than the 'regular segment'.

There is a growing view that demographic and socio-economic variables are insufficient for segmentation. There is an increasing consensus that psychological and behavioural variables are of particular importance (Gerpott and Mahmudova, 20Io; Tabi et al., 20I4). For instance, consumers who are involved in pro-environmental activities have a higher propensity to purchase green electricity (Gerpott and Mahmudova, 20IO). Van Birgelen et al. (20II) show through their study of voluntary carbon offsetting that 'air travellers who behave in environmentally friendly ways in areas other than aviation (for instance recycling) appear to transfer their behaviour to their air travel' (p. I28). We thus hypothesize the following.

$\mathrm{H}_{4}$ : The 'green segment' in air travel is more likely (a) to recycle, (b) to have adopted a green electricity product, (c) to purchase regional food, (d) to boycott companies with low environmental standards, (e) to purchase fair trade products, (f) to purchase energy efficient products and (g) to purchase durable products than the 'regular segment'.

Second, the choice of air travel class may also be associated with the propensity to purchase green products in travel. Sorensen and Lucas (20I4) argue that 'high value customers' (e.g. business class passengers) have a high tendency to pay for general supplementary services in air travel. These findings may also be applied to green products in air travel. This leads us to the following hypothesis.

$\mathrm{H}_{5}$ : The 'green segment' in air travel travels more frequently in first and business class than the 'regular segment'.

\section{Sample and Methodology}

\section{Sample}

We recruited respondents in October 20I4 through an online mailing to Io 000 Swiss International Air Line customers in Switzerland. I428 started to participate in the survey, and IIO2 completed it. For the data analysis, only those respondents who were interested in buying any of the additional airline services offered and who thus participated in the adaptive choice-based conjoint analysis tournament section were included. Of the respondents, 29I $(26.4 \%)$ were not at all interested in buying any of the offered services and were thus excluded from the analysis. Finally, 8II completed surveys were available for the analysis.

\section{Adaptive Choice-Based Conjoint Analysis}

We applied an adaptive choice-based conjoint analysis (ACBC), which has been applied by several authors in recent years (Boesch and Weber, 20I2; Heinzle et al., 20I3). ACBC surveys aim to mimic decision-making processes that influence real-world choices as closely as possible, as they adapt the design of the choice experiment to the specific preferences of each individual respondent. This method is particularly suitable when decision-makers employ non-compensatory decision-making rules, assuming that people make complex choices by establishing a consideration set (commonly applying cut-off rules) and then choosing an option within this set (Johnson and Orme, 2007). 


\section{Variables}

We investigated potential green products through an analysis of corporate social responsibility reports, internet searches, informal interviews with airline managers and two focus groups with MBA students. Prices for product bundles were estimated through comparisons with existing products and interviews. Based on the findings of the interviews and focus groups five attributes were included in the final ACBC: meals, hotel transfers, carbon offsets, travel packs and price. This led to a symmetric conjoint design with five attributes and three levels per attribute (Table I). Carbon offsets have long been advocated by a range of stakeholders as a useful means to tackle the climate impact of air travel (McKercher et al., 20I0). Voluntary carbon offsetting is usually performed through the Clean Development Mechanism, focusing on developing countries. The interviews, however, suggested that airline passengers prefer offsetting in the home market (i.e. Switzerland). Thus, offsetting in India and in Switzerland were included as attribute levels, in addition to the option of not including any offsetting services. Moreover, it has been noted that transfer to and from airports plays an important role in reducing carbon emissions (Ryley et al., 2013). We included two attribute levels to test the appeal of airport transport: transport in a minivan and transport in a carbon-free minivan. Two additional variables were included that do not directly relate to carbon emissions of air travel but have an impact on waste and resource use. First, inflight food and drink has been found to have a substantial influence on 'customer experience' (Laming and Mason, 20I4). The interviewees showed considerable interest in purchasing organic meals on board. Based on the interviews, we decided to include a standard meal in the standard airfare. In our example, the passenger had the option to purchase a premium meal (beef with risotto or a vegetarian option) or an organic premium meal (organic beef with risotto, locally produced, or a vegetarian option). Second, the ability to purchase a travel pack made of sustainable materials was noted by our interviewees. A standard and an organic travel pack were included as attribute levels, in addition to the option of not including any travel pack. As the base price for a bundle of different supplementary services, we chose $60 \mathrm{CHF}$ as the mid-price and then varied the price by a randomly drawn price variation from $-30 \%$ to $+30 \%$. We rounded the prices, after being altered randomly, to the nearest CHF 5 .

\section{Design and Data Analysis}

The Sawtooth Software module SSI Web was used to program the survey in a web-based version. The survey consisted of three parts. First, interviewees were asked about their travel behaviour (class, nature, frequency). The second part constituted the ACBC survey. Respondents were presented with a hypothetical situation in which they were asked to assume that they had just purchased a four-hour flight in the economy class for CHF 500. They were

\begin{tabular}{|c|c|c|}
\hline Attribute & Description & Levels \\
\hline Meal & $\begin{array}{l}\text { possibility of purchasing an upgraded meal } \\
\text { (two options) - a standard meal was assumed } \\
\text { to be included in the flight }\end{array}$ & $\begin{array}{l}\text { standard meal } \\
\text { premium meal } \\
\text { organic premium meal }\end{array}$ \\
\hline Hotel transfer & $\begin{array}{l}\text { possibility of purchasing a direct hotel } \\
\text { transfer in a minivan }\end{array}$ & $\begin{array}{l}\text { no transfer } \\
\text { transfer in minivan } \\
\text { transfer in electric minivan }\end{array}$ \\
\hline Carbon offset & $\begin{array}{l}\text { possibility of offsetting carbon emissions from } \\
\text { the flight through environmental projects }\end{array}$ & $\begin{array}{l}\text { no offsetting } \\
\text { offsetting in India } \\
\text { offsetting in Switzerland }\end{array}$ \\
\hline Travel pack & $\begin{array}{l}\text { possibility of purchasing a 'travel pack' with hand } \\
\text { sanitizer, toothbrush, (green) travel guide included }\end{array}$ & $\begin{array}{l}\text { no travel pack } \\
\text { travel pack } \\
\text { green travel pack }\end{array}$ \\
\hline Price & price for a bundle of different supplementary services & $60 \mathrm{CHF}$ as mid-point, price ranges of $\pm 30 \%$ \\
\hline
\end{tabular}

Table 1. Conjoint design 


\section{Willingness to Pay for Green Products in Air Travel}

informed that they now had the opportunity to purchase additional supplementary services. The questionnaire began with a 'screening section', where respondents were presented with four service bundles and were requested to declare whether they would consider a service bundle at a given price as an attractive option. The goal of this section was to determine whether air passengers were using any non-compensatory screening rules by identifying any unacceptable product attribute. Non-compensatory screening rules are applied when decision-makers first remove choice options with unacceptable levels from their consideration set and then only make choices among those options that are in line with such screening rules (Johnson and Orme, 2007). In the last step ('choice tournament'), respondents were presented with product concepts (that only included acceptable attributes) and were asked which of the bundles, among three randomly chosen concepts, they would most probably choose to buy (Johnson and Orme, 2007). In a third section, respondents were asked a set of demographic questions and questions related to their environmental related behaviour. A five-point Likert-type scale was applied to determine the frequency of performing a set of several distinctive environmental behaviours (see Table 7 later for the items included in the survey). Adoption of green electricity was measured with a categorical variable (yes, no, don't know).

For the data analysis, we estimate individual-level part-worth utilities of the air passengers from the observed choices through the hierarchical Bayes estimation (HB) method. Part-worth utilities indicate the relative desirability of an attribute level. To make the findings comparable across individuals, we convert part-worths into quantities such as relative importances, market shares and monetary values. Relative importance scores are measured from relative part-worth utility ranges (Orme, 20I0). We use two different approaches to determine the economic value of specific attribute levels or complete service bundles. First, we measure how much individuals would be willing to pay in exchange for an improvement, in the level of a distinctive attribute. This approach is also called the marginal WTP (MWTP) calculation (Orme, 20I0). This approach involves taking differences in utilities between two different attribute levels and dividing that sum by the price slope (Orme, 20I0). The results of such an approach, however, should be cautiously interpreted because they do not take into account the impact of competition in the market and may yield heavy-tailed posterior distributions (see, e.g., Sonnier et al., 2007). The value of product enhancement can be better assessed through market simulations (Orme, 20I0). We therefore use share of preference simulations to model respondents' responses to different product bundles. Furthermore, we use the part-worth utility scores of the ACBC for market segmentation purposes: market heterogeneity in attribute preferences is captured across a full set of attributes in order to identify groups of individuals who share similar preference structures (DeSarbo et al., 1995). By using Sawtooth's Convergent Cluster and Ensemble Analysis (CCEA), we then identify groups with similar preference structures (Orme and Johnson, 2008). Once segments of individuals are identified, we characterize these clusters in terms of demographic and behavioural variables.

\section{Results}

\section{Preferences for Additional Airline Services}

Table 2 gives an overview of the zero-centered utilities and the corresponding standard deviations of each attribute level as measured by the HB model for the average sample. Table 2 also shows the attribute importance scores as well as what attribute levels respondents considered as unacceptable.

For the four attributes of on-board catering, hotel transfer, carbon offsetting and travel pack, the part-worth type of utility estimation is chosen (i.e., a separate utility for each attribute level is estimated). The effect of overall price is estimated using a single linear coefficient that reflected the slope of price. In order to resolve out-of-order utility relationships for those attributes with an a priori preference order, we impose utility constraints on orders of utilities within all attributes. Regarding the attribute carbon offset, we only enforce the constraint that having a carbon offset (in both India and Switzerland) included in the service package should be preferred over no carbon offset included. No ranking order between carbon offset in India and Switzerland is applied. 


\begin{tabular}{|c|c|c|c|c|c|}
\hline Attributes and levels & Importance (\%) & SD (\%) & Average utilities & SD & Unacceptable attribute levels (\%) \\
\hline On-board catering & 11.9 & $(10.3)$ & & & \\
\hline Standard set meal & & & -34.0 & $(31.7)$ & 10.1 \\
\hline Premium set meal & & & 8.4 & $(18.6)$ & 0.7 \\
\hline Organic premium set meal & & & 25.6 & $(22.3)$ & 0.0 \\
\hline Hotel transfer & 20.7 & $(11.6)$ & & & \\
\hline No hotel transfer & & & -61.0 & $(36.6)$ & 18.7 \\
\hline Standard hotel transfer & & & 18.2 & $(26.3)$ & 1.0 \\
\hline Carbon-free hotel transfer & & & 42.8 & $(26.1)$ & 0.0 \\
\hline Carbon offsetting & 17.4 & $(12.4)$ & & & \\
\hline No carbon offsetting & & & $-39 \cdot 9$ & $(33.6)$ & 8.6 \\
\hline Carbon offsetting in India & & & -3.7 & $(31.3)$ & 1.0 \\
\hline Carbon offsetting in Switzerland & & & 43.6 & $(34 \cdot 7)$ & 0.0 \\
\hline Travel pack & 5.6 & $(5 \cdot 5)$ & & & \\
\hline No travel pack & & & -15.2 & $(17.2)$ & 5.1 \\
\hline Regular travel pack & & & 2.5 & $(9.4)$ & 0.1 \\
\hline Eco-friendly travel pack & & & 12.7 & $(11.2)$ & 0.0 \\
\hline Price & $44 \cdot 3$ & $(17.1)$ & & & \\
\hline 40 Swiss Francs & & & 110.8 & $(42.8)$ & \\
\hline 80 Swiss Francs & & & -110.8 & $(42.8)$ & \\
\hline None & & & 41.8 & $(101.8)$ & \\
\hline
\end{tabular}

Table 2. Results of the HB model for the entire sample $(n=811)$

${ }^{a}$ Number of respondents who regard given attribute levels as 'unacceptable' when choosing a bundle of additional airline services. The average root likelihood (RLH) was used as a measure of fit to assess the convergence of HB estimates (Orme, 2010). In this study, it was predicted that each alternative would be chosen with a probability of $1 / 3$. RLH was 0.63 for this model, indicating a good fit of the model.

The most important attribute in air passengers' service package bundling choices is the price (44.3\%), followed by hotel transfer (20.7\%), carbon offsetting (I7.4\%), on-board catering (II.9\%) and travel pack (5.6\%). Of all of the respondents that are interested in buying additional airline services, I8.7\% regard 'no hotel transfer' as unacceptable, whereas io.1\% regard the standard set meal as unacceptable. Moreover, only $8.6 \%$ of the respondents consider 'no carbon offsetting' as an unacceptable attribute level.

\section{Results of the Segmentation Analysis}

CCEA is used in order to discover groups within data by making use of each respondent's part-worth utility estimates of all attributes as a criterion for classifying respondents into groups. We chose a two-class model that includes (I) air passengers who consider environmental attributes to be very important product features ('green segment') and (2) air passengers who consider environmental attributes as less relevant in their choice of additional airline service bundles ('regular segment').

I60 passengers ( $20 \%$ of passengers who are interested in supplementary airline services) are identified as potential purchasers of additional green airline services, and 65I $(80 \%)$ are identified as being unlikely to be interested in green attributes when buying additional airline services. Table 3 displays the results of the HB model for the two types of airlines passenger. Mann-Whitney U-tests show that significant differences can be found between the two segments with regard to the importance scores of all attributes $(p<0.00 \mathrm{I})$, except for hotel transfer $(p=0.664)$.

\section{Calculation of Marginal Willingness to Pay (MWTP)}

Table 4 shows the mean and median prices that premium air passengers are willing to pay for an upgrade in attribute level. Mann-Whitney U-tests show that respondents belonging to the 'green segment' are willing to pay 
Willingness to Pay for Green Products in Air Travel

\begin{tabular}{|c|c|c|c|c|c|c|c|c|}
\hline \multirow[b]{2}{*}{ Attribute and attribute levels } & \multicolumn{2}{|c|}{$\begin{array}{l}\text { Regular segment } \\
\qquad(n=651)\end{array}$} & \multicolumn{2}{|c|}{$\begin{array}{l}\text { Green segment } \\
\qquad(n=160)\end{array}$} & \multicolumn{2}{|c|}{$\begin{array}{l}\text { Regular segment } \\
\qquad(n=651)\end{array}$} & \multicolumn{2}{|c|}{$\begin{array}{l}\text { Green segment } \\
\qquad(n=160)\end{array}$} \\
\hline & $\begin{array}{c}\text { Importance } \\
(\%)\end{array}$ & SD (\%) & $\begin{array}{c}\text { Importance } \\
(\%)\end{array}$ & SD (\%) & Average utilities & SD & Average utilities & SD \\
\hline On-board catering & 10.5 & $(8.7)$ & 17.7 & (13.9) & & & & \\
\hline Standard set meal & & & & & -30.3 & $(26.6)$ & -49.0 & $(44.1)$ \\
\hline Premium set meal & & & & & 8.0 & $(15.5)$ & 9.7 & $(28.2)$ \\
\hline Organic premium set meal & & & & & 22.3 & $(18.7)$ & 39.3 & $(29.7)$ \\
\hline Hotel transfer & 20.6 & $(11.5)$ & 21.2 & (12.0) & & & & \\
\hline No hotel transfer & & & & & -62.1 & $(37.1)$ & -56.2 & (33.9) \\
\hline Standard hotel transfer & & & & & 21.0 & $(24.7)$ & 6.4 & $(29.1)$ \\
\hline $\mathrm{CO}_{2}$-free hotel transfer & & & & & 41.0 & $(23.9)$ & 49.8 & $(32.7)$ \\
\hline Carbon offsetting & 14.3 & (9.7) & 30.1 & (14.1) & & & & \\
\hline No carbon offsetting & & & & & -32.6 & $(25.9)$ & -69.6 & $(43.7)$ \\
\hline Carbon offsetting in India & & & & & -3.2 & $(24.9)$ & -5.9 & (48.7) \\
\hline Carbon offsetting in Switzerland & & & & & 35.7 & $(27.7)$ & 75.5 & $(41.5)$ \\
\hline Travel pack & 4.8 & (4.9) & 8.6 & $(6.6)$ & & & & \\
\hline No travel pack & & & & & -13.3 & $(15.5)$ & -22.6 & $(21.1)$ \\
\hline Regular travel pack & & & & & 2.5 & (8.4) & 2.1 & $(12.8)$ \\
\hline Eco-friendly travel pack & & & & & 10.8 & $(9.6)$ & 20.5 & $(13.6)$ \\
\hline Price & 49.7 & $(13.3)$ & 22.4 & (13.3) & & & & \\
\hline $40 \mathrm{CHF}$ & & & & & 124.3 & $(33.2)$ & 56.0 & (32.7) \\
\hline $80 \mathrm{CHF}$ & & & & & -124.3 & $(33.2)$ & -6.0 & $(32.7)$ \\
\hline
\end{tabular}

Table 3. Results for the two segments

\begin{tabular}{|c|c|c|c|c|c|}
\hline & \multicolumn{2}{|c|}{ Regular segment $(n=651)$} & \multicolumn{2}{|c|}{ Green segment $(n=160)$} & \multirow[t]{2}{*}{$p$-value ${ }^{a}$} \\
\hline & Mean (SD) & Median & Mean (SD) & Median & \\
\hline Standard set meal vs premium set meal & $7.6(10.8)$ & 3.6 & $40.1(80.6)$ & 14.1 & $<0.001^{k * *}$ \\
\hline Premium set meal vs organic premium set meal & $2.8(6.0)$ & 1.1 & $28.0(66.3)$ & 6.5 & $<0.001^{* *}$ \\
\hline No hotel transfer vs standard hotel transfer & $15.3(13.8)$ & 11.3 & $35.1(50.3)$ & 19.7 & $<0.001^{* * *}$ \\
\hline Standard hotel transfer vs $\mathrm{CO}_{2}$ free hotel transfer & $4.2(8.5)$ & 1.2 & $35.4(66.9)$ & 8.5 & $<0.001^{* *}$ \\
\hline No carbon offsetting vs carbon offsetting in India & $5.7(9.6)$ & 1.5 & $49.0(107.1)$ & 10.1 & $<0.001^{* * *}$ \\
\hline Carbon offsetting in India vs carbon offsetting in Switzerland & $7.1(10.4)$ & 5.1 & $53.8(97.0)$ & 28.1 & $<0.001^{* *}$ \\
\hline No travel pack vs regular travel pack & $3.1(6.7)$ & 1.3 & $17.7(49.0)$ & 4.8 & $<0.001^{* *}$ \\
\hline Regular travel pack vs eco-friendly travel pack & $1.7(3.0)$ & 0.9 & $15.6(29.5)$ & 5.1 & $<0.001^{* *}$ \\
\hline
\end{tabular}

Table 4. Mean and median MWTP in CHF of the difference in attribute level utility

${ }^{a}$ Statistical significance between the groups is calculated based on Mann-Whitney U-tests.

*** $<0.001$.

significantly higher premiums for all upgrades in attribute level than respondents belonging to the 'regular segment' $(p<0.00 \mathrm{I})$. As seen in Table 4 , the median values of the MWTP are much smaller than the mean MWTP values. The reason for this is that some air passengers are relatively price insensitive. In such a case, the monetary equivalent for incremental features for a small share of the respondents becomes very large, which has a strong impact on the mean. In contrast, extreme values do not affect the median as strongly as they do the mean, hence we focus on the median for our interpretation. 


\section{Economic Validation of Additional Services via a Market Simulation}

Share of preference simulations are used to model the two segments' responses to hypothetical bundling services. The estimated part-worth utilities from the HB estimation method are used as the basis for estimating these shares of preference. The share of preference results represent the percentage of air passengers who would prefer one bundle, assuming that a given set of bundles would be the only choice available.

In the following scenario, four competing products, i.e. attribute bundles, are defined (Table 5). The premium of the products under consideration is modified until an equal share of preference (i.e. $25 \%$ ) for all four products is achieved. Because the part-worth profiles for the price attribute were captured as a linear variable, extrapolation with straight lines is used. Table 5 later reports the results of this analysis, which indicates that the 'green segment' displays a considerably higher WTP for green bundles compared with the 'regular segment'.

\section{Segments Analysed by Socio-demographic and Behavioural Characteristics}

As a next step, we determine whether the 'regular segment' differs significantly from the 'green segment' in terms of the socio-demographic and behavioural characteristics. Tables 6-9 provide an overview of the results of the investigated variables and detail the $p$-levels and the test statistics of selected pairwise comparisons. None of the socio-demographic characteristics significantly differ between the two segments. However, analysing the behavioural characteristics paints a different picture. It can be seen that environmental behaviour differs significantly between the two segments, except for recycling behaviour and purchase of durable and energy-efficient products.

\section{Discussion}

We find support for Нr. The findings suggest that $20 \%$ of those passengers who are interested in purchasing supplementary services have a strong preference for green airline services ('green segment'). Our analysis indicates that the 'green segment' displays a significantly higher WTP for green products than the 'regular segment'. In total, approximately $\mathrm{I} 4.5 \%$ of all airline passengers surveyed (I60 respondents belonging to the green segment divided by IIO2 participants in the study) display a significant WTP for green products. The overall demand for supplementary services in air travel is in line with previous studies. The fact that $26.4 \%$ of the respondents were not at all interested in any supplementary services in air travel matches the analysis by Wittmer and Rowley (20I4), who report a figure of $26.5 \%$.

We fail to find support for H2. The 'regular segment' does not display a higher WTP for green products with additional benefits (status, heath) compared with pure green products. The data also indicates which green services were particularly important for the 'green segment'. Carbon offsetting seems to be of highest importance for the green segment. It is noteworthy that carbon offset projects in the passengers' home market (Switzerland) increases customer value substantially more than carbon offset projects in developing countries (India). This finding stands in stark contrast to the findings of Choi and Ritchie (20I4), who find a higher WTP for international

\begin{tabular}{|c|c|c|c|c|}
\hline & $\begin{array}{l}\text { Product } 1 \text { : no } \\
\text { additional service }\end{array}$ & $\begin{array}{l}\text { Product 2: standard } \\
\text { service bundle }\end{array}$ & $\begin{array}{l}\text { Product 3: Green } \\
\text { Bundle I }\end{array}$ & $\begin{array}{l}\text { Product 4: Green } \\
\text { Bundle II }\end{array}$ \\
\hline On-board catering & standard set meal & premium set meal & organic premium set meal & organic premium set meal \\
\hline Hotel transfer & no transfer & standard hotel transfer & $\mathrm{CO}_{2}$-free hotel transfer & $\mathrm{CO}_{2}$-free hotel transfer \\
\hline Carbon offsetting & no carbon offsetting & no carbon offsetting & compensation in India & compensation in Switzerland \\
\hline Travel pack & no travel pack & regular travel pack & eco-friendly travel pack & eco-friendly travel pack \\
\hline Share of preference & $25 \%$ & $25 \%$ & $25 \%$ & $25 \%$ \\
\hline Price regular segment & o $\mathrm{CHF}$ & $19.5 \mathrm{CHF}$ & $29.0 \mathrm{CHF}$ & $35.6 \mathrm{CHF}$ \\
\hline Price green segment & o $\mathrm{CHF}$ & $39.4 \mathrm{CHF}$ & $93.8 \mathrm{CHF}$ & $126.1 \mathrm{CHF}$ \\
\hline
\end{tabular}

Table 5. Share of preference simulation 


\begin{tabular}{|c|c|c|c|}
\hline & Regular segment $(n=651)$ & Green segment $(n=160)$ & $p$-value \\
\hline Gender & & & 0.698 \\
\hline Male (\%) & 60.8 & 62.5 & \\
\hline Female (\%) & 39.2 & 37.5 & \\
\hline Age (average) & 47.0years (SD: 13.0 years) & 46.6 years (SD: 12.0 years) & 0.743 \\
\hline Household income & & & 0.461 \\
\hline Below CHF 6000 (\%) & 10.1 & 8.8 & \\
\hline CHF 6000-10 000 (\%) & 30.6 & 28.8 & \\
\hline Above CHF 10 ooo (\%) & 48.1 & $54 \cdot 4$ & \\
\hline Not specified (\%) & 11.2 & 8.1 & \\
\hline Level of education & & & 0.986 \\
\hline Vocational training (\%) & 22.6 & 23.8 & \\
\hline Secondary-school examination (\%) & 11.1 & 10.6 & \\
\hline University/college (\%) & 56.4 & 56.3 & \\
\hline Other (\%) & 10.0 & 9.4 & \\
\hline Household size & & & 0.232 \\
\hline 1 person (\%) & 22.4 & 25.0 & \\
\hline 2 persons (\%) & 48.5 & 40.6 & \\
\hline 3 persons (\%) & 14.1 & 13.1 & \\
\hline 4 persons (\%) & 11.1 & 15.0 & \\
\hline 5 persons or more $(\%)$ & 3.8 & 6.3 & \\
\hline
\end{tabular}

Table 6. Descriptive statistics and significance tests (socio-demographic variables)

offsets in comparison with domestic projects. Similarly, this finding does not confirm the findings of MacKerron et al. (2009), who find a higher WTP for carbon offsets associated with social co-benefits. One possible interpretation of this finding is that Swiss customers prefer Swiss-based projects, in line with the well-documented home-bias in consumption (McCallum, I995). Moreover, both segments show considerable interest in hotel transfer offerings, challenging the findings of O'Connell and Warnock-Smith (2013). More specifically, the 'green segment' is willing to pay a considerable premium for carbon-free transportation. This might be one pathway to increase the uptake of more sustainable ground transportation, as advocated by Ryley et al. (2013). Finally, the travel pack does not seem to substantially increase customer value for either segment, with the green segment being only marginally more interested.

We fail to support $\mathrm{H}_{3} \mathrm{a}-\mathrm{H}_{3}$. The segmentation analysis reveals that the green segment does not differ in terms of demographic data. This is in line with recent research on environmental segments, such as that by Tabi et al. (20I4). This however stands in stark contrast to the findings of Mair (20II) that socio-demographic criteria do explain a higher WTP for carbon offsets.

We fail to find support for $\mathrm{H}_{4} \mathrm{a}, \mathrm{H}_{4} \mathrm{f}$ and $\mathrm{H}_{4}$ g, but find support for $\mathrm{H}_{4} \mathrm{~b}-\mathrm{H}_{4}$ e. Similarly to the study by Van Birgelen et al. (20II) on carbon offsetting, we can confirm that customers who behave in an environmentally friendly way in selected other areas (e.g. buying regional products, boycotting companies, buying green electricity etc.) transfer their green behaviour to their air travel behaviour as well. One explanation why we did not find any significant difference between the two segments related to buying more energy-efficient or durable products could be that these purchase acts bring along financial co-benefits. Boycotting companies that do not act in an environmental friendly way or purchasing green electricity products, just to name two examples, are voluntary performances that are not related to any co-benefits, which triggers mental self-justification processes. This increased mental activity increases the salience of abstract values, attitudes and norms that serve as the justification of the subsequent behaviour (Homer and Kahle, I988; Stern, I992, as cited by Thøgersen, I999), such as purchasing green products in aviation. Besides energy-efficient and durable products that provide financial co-benefits, recycling $\left(\mathrm{H}_{4} \mathrm{a}\right)$ is another outlier in this respect, as a higher propensity to recycle is not related to a higher propensity to purchase green products in air 
G. Hinnen et al.

\begin{tabular}{|c|c|c|c|}
\hline & Regular segment $(n=651)$ & Green segment $(n=160)$ & $p$-value \\
\hline Recycling behaviour ${ }^{\mathrm{a}}$ & M: 1.23 (SD: 0.57) & M: 1.21 (SD: 0.52) & 0.750 \\
\hline Energy efficient purchase behaviour & M: 1.98 (SD: 0.95$)$ & M: 1.84 (SD: 0.86$)$ & 0.137 \\
\hline Durable products ${ }^{c}$ & $M: 1.78$ (SD: 0.75$)$ & M: 1.73 (SD: 0.69$)$ & 0.640 \\
\hline Regional products ${ }^{\mathrm{d}}$ & $M: 2.10$ (SD: 0.78$)$ & M: 1.84 (SD: 0.71$)$ & $<0.0001^{k * x}$ \\
\hline Boycott companies $^{e}$ & $M: 2.50$ (SD: 1.02) & M: 2.29 (SD: 0.97) & $0.017^{*}$ \\
\hline Fair-trade products ${ }^{\mathrm{f}}$ & M: 2.19 (SD: 0.87) & M: 1.99 (SD: 0.78$)$ & $0.008^{*}$ \\
\hline Adoption of green electricity & & & 0.063 \\
\hline Yes (\%) & 29.8 & 39.4 & \\
\hline No $(\%)$ & 51.0 & 43.1 & \\
\hline I don't know (\%) & 19.2 & 17.5 & \\
\hline Number of travels abroad per year & M: 11.2 (SD: 12.4) & M: 11.9 (SD: 10.0) & 0.130 \\
\hline Number of flights per year & $M: 7.6$ (SD: 7.3$)$ & $M: 7.8$ (SD: 5.8$)$ & 0.264 \\
\hline Reason for travel & & & 0.412 \\
\hline Private (\%) & 67.0 & 66.9 & \\
\hline Business (\%) & 32.0 & 33.1 & \\
\hline Don't know (\%) & 1.1 & 0.0 & \\
\hline
\end{tabular}

Table 7. Descriptive statistics and significance tests (behavioural variables)

$* p<0.05, * * p<0.001$.

The test of significance for the categorical variables was a chi square statistic. The test of significance for the continuous variables was either a $t$-test (when values were normally distributed) or a Mann-Whitney $U$-test (when values were not normally distributed). aParticipants were asked to indicate how frequently ( 1 , always, to 5 , never) they showed the following two behaviours: (1) 'I collect and recycle waste paper'; (2) 'I collect and recycle PET bottles'. The two items were averaged to assess people's recycling behaviour.

bParticipants were asked to indicate how frequently (1, always, to 5 , never) they showed the following behaviour: 'When I buy electrical appliances, I consciously pay attention to the level of energy consumption'.

${ }^{C}$ Participants were asked to indicate how frequently (1, always, to 5 , never) they showed the following behaviour: 'When I buy products, I consciously pay attention to durability aspects'.

${ }^{d}$ Participants were asked to indicate how frequently (1, always, to 5 , never) they showed the following behaviour: 'I often buy products such as wine, fruits or vegetables from the region I live in'.

eParticipants were asked to indicate how frequently (1, always, to 5 , never) they showed the following behaviour: 'I often boycott companies that harm the environment'.

fParticipants were asked to indicate how frequently (1, always, to 5 , never) they showed the following behaviour: 'I often buy fair-traded products'.

\begin{tabular}{|c|c|c|c|c|}
\hline & & $\begin{array}{l}\text { Regular segment } \\
\text { (\%) }(n=651)\end{array}$ & $\begin{array}{l}\text { Green segment } \\
\quad(\%)(n=158)\end{array}$ & $p$-value \\
\hline \multirow{2}{*}{$\begin{array}{c}\text { Choice of travel class when } \\
\text { flying for private reasons }\end{array}$} & First class or business class & 8.9 & 13.3 & \multirow[t]{2}{*}{0.101} \\
\hline & Economy class & 91.1 & 86.7 & \\
\hline
\end{tabular}

Table 8. Choice of travel when flying for private reasons

Only those respondents were included who fly for private reasons. The test of significance for the categorical variable was a chisquare statistic.

travel. We speculate that this is the case because recycling has a long tradition in Switzerland and is a feature of everyday life (Schenk, 2009).

We find some support for H6: the 'green segment' displays a significantly higher share of passengers who fly in business class, albeit only significant at the o.Io level when flying for private reasons. A possible explanation for this finding is that such business travellers display a guilty conscience due to their relatively luxurious mode of travel and are thus more willing to purchase green products. For instance, it has been asserted that carbon offsets address 'green guilt' rather than changing behaviour (Kotchen, 2009). 


\begin{tabular}{llcc}
\hline & & $\begin{array}{c}\text { Regular segment } \\
(\%)(n=462)\end{array}$ & $\begin{array}{c}\text { Green segment } \\
(\%)(n=115)\end{array}$ \\
\hline $\begin{array}{l}\text { Choice of travel class when } \\
\text { flying for business reasons }\end{array}$ & First class or business class & 18.0 & 29.6 \\
\hline
\end{tabular}

Table 9. Choice of travel when flying for business reasons

Only those respondents were included who fly for business reasons. The test of significance for the categorical variable was a chisquare statistic.

$* p<0.10$.

\section{Conclusion}

This paper explores the demand for green products in air travel. We find that approximately $20 \%$ of air travellers in Switzerland who are interested in buying additional airline services display a high WTP for green products. In particular, carbon offsets and carbon-free ground transport are of high importance for the 'green segment'. Our study makes two key contributions. First, in line with recent research on green marketing (Tabi et al., 20I4), we provide additional evidence that this 'green segment' differs from the regular segment not in terms of socio-economic criteria, but in terms of behavioural criteria. Second, our findings indicate that a subset of passengers is willing to pay a considerable premium for green air travel. We thereby expand the discussion on sustainable air transport to the role of the passengers; contemporary research primarily focuses on the role of the regulator (e.g. Vespermann and Wittmer, 20II) and corporate customers (e.g. Oberhofer and Fürst, 20I3).

Our research is characterized by a number of limitations that provide important starting points for further research. First, the findings are based on air travellers in Switzerland. It would be especially interesting to examine whether the underlying culture and development status affect environmental behaviour in air travel (Soyez, 20I2). Second, we build our research on data from average travellers on a medium-sized network carrier. Future research could focus on other business models (e.g. low-cost carriers) and travellers (e.g. high-value customers). Third, the ACBC method is not without fault. The choice of attributes and prices, in particular, can affect outcomes. Green products should, therefore, be tested together with more conventional products (e.g. travel insurance) to reveal their importance relative to standard services. Fourth, we only tested for behavioural and demographic criteria. Future studies should also address psychographic criteria.

\section{References}

Berman B. 20I5. How to compete effectively against low-cost competitors. Business Horizons 58(I): 87-97.

Blasch J, Farsi M. 20I3. Context effects and heterogeneity in voluntary carbon offsetting - a choice experiment in Switzerland. Journal of Environmental Economics and Policy 3(I): I-24.

Boesch I, Weber M. 20I2. Processor's preferences and basic differentiation strategies for potatoes, milk, and wheat in Switzerland. Journal of Agricultural and Food Industrial Organization Io(I): I-22.

Brons M, Pels E, Nijkamp P, Rietveld P. 2002. Price elasticities of demand for passenger air travel: a meta-analysis. Journal of Air Transport Management 8(3): 165-I75.

Choi AS, Ritchie BW. 20I4. WTP for flying carbon neutral in Australia: an exploratory study of offsetter profiles. Journal of Sustainable Tourism 22(8): I236-I256.

De Pelsmacker P, Driesen L, Rayp G. 2005. Do consumers care about ethics? WTP for fair-trade coffee. Journal of Consumer Affairs 39(2): 363-385.

DeSarbo W, Ramaswamy V, Cohen S. I995. Market segmentation with choice-based conjoint analysis. Marketing Letters 6(2): I37-I47.

Diaz-Rainey I, Ashton JK. 20II. Profiling potential green electricity tariff adopters: green consumerism as an environmental policy tool? Business Strategy and the Environment 20(7): 456-470.

Ek K, Söderholm P. 2008. Norms and economic motivation in the Swedish green electricity market. Ecological Economics 68(I/2): I69-182.

Fisher C, Bashyal S, Bachman B. 20I2. Demographic impacts on environmentally friendly purchase behaviors. Journal of Targeting, Measurement and Analysis for Marketing 20(3/4): I72-I84.

Font X, Tapper R, Schwartz K, Kornilaki M. 2008. Sustainable supply chain management in tourism. Business Strategy and the Environment I7(4): 260-27I. 


\section{G. Hinnen et al.}

Gerpott TJ, Mahmudova I. 20I0. Determinants of green electricity adoption among residential customers in Germany. International Journal of Consumer Studies 34(4): 464-473.

Griskevicius V, Tybur JM, Van den Bergh B. 20I0. Going green to be seen: status, reputation, and conspicuous conservation. Journal of Personality and Social Psychology 98(3): 392-404.

Hampl N, Loock M. 2013. Sustainable development in retailing: what is the impact on store choice? Business Strategy and the Environment 22(3): 202-2I6.

Heinzle SL, Boey Ying Yip A, Low Yu Xing M. 2013. The influence of green building certification schemes on real estate investor behaviour: evidence from Singapore. Urban Studies 50(4): I-I8.

Homer PM, Kahle LR. I988. A structural equation test of the value-attitude-behavior hierarchy. Journal of Personality and Social Psychology 54(4): $638-646$.

Johnson RM, Orme BK. 2007. A new approach to adaptive CBC. Sawtooth Software Research Paper Series. Sawtooth Software: Sequim, WA.

Kaenzig J, Heinzle SL, Wüstenhagen R. 20I3. Whatever the customer wants, the customer gets? Exploring the gap between consumer preferences and default electricity products in Germany. Energy Policy 53: 3II-322.

Kotchen MJ. 2009. Offsetting green guilt. Stanford Social Innovation Review 7(2): 26-3I.

Laming C, Mason K. 20I4. Customer experience - an analysis of the concept and its performance in airline brands. Research in Transportation Business and Management I0: $15-25$.

MacKerron GJ, Egerton C, Gaskell C, Parpia A, Mourato S. 2009. WTP for carbon offset certification and co-benefits among (high-) flying young adults in the UK. Energy Policy 37(4): 1372-I38I.

Mair J. 20II. Exploring air travellers' voluntary carbon-offsetting behaviour. Journal of Sustainable Tourism I9(2): 2I5-230.

McCallum J. I995. National borders matter: Canada-U.S. regional trade patterns. American Economic Review 85(3): 615-623.

McKercher B, Prideaux B, Cheung C, Law R. 20I0. Achieving voluntary reductions in the carbon footprint of tourism and climate change. Journal of Sustainable Tourism I8(3): 297-3I7.

McLennan C-LJ, Becken S, Battye R, So KKF. 20I4. Voluntary carbon offsetting: who does it? Tourism Management 45: I94-I98.

Metz B, Davidson OR, Bosch P, Dave R, Meyer L. 2007. Climate Change 2007: Mitigation of Climate Change. Working Group III Contribution to the Fourth Assessment Report of the Intergovernmental Panel on Climate Change. www.ipcc.ch [22 December 20I4].

O'Connell JF, Warnock-Smith D. 20I3. An investigation into traveller preferences and acceptance levels of airline ancillary revenues. Journal of Air Transport Management 33: I2-2I.

Oberhofer P, Fürst E. 2013. Sustainable development in the transport sector: influencing environmental behaviour and performance. Business Strategy and the Environment 22(6): 374-389.

Orme B. 20I0. Getting Started with Conjoint Analysis: Strategies for Product Design and Pricing Research. Research Publishers: Madison, WI.

Orme B, Johnson R. 2008. Improving K-Means Cluster Analysis: Ensemble Analysis instead of Highest Reproducibility Replicates. Sawtooth Software Research Paper Series. Sawtooth Software: Sequim, WA.

Ottman JA, Stafford ER, Hartman CL. 2006. Avoiding green marketing myopia: ways to improve consumer appeal for environmentally preferable products. Environment 48(5): 22-36.

Ryley T, Elmirghani J, Budd T, Miyoshi C, Mason K, Moxon R, Ahmed I, Qazi B, Zanni A. 20I3. Sustainable development and airport surface access: the role of technological innovation and behavioral change. Sustainability 5(4): I6I7-I63I.

Schenk T. 2009. Der grosse Recycling Report. NZZ Folio. NZZ: Zurich.

Sonnier G, Ainslie A, Otter T. 2007. Heterogeneity distributions of willingness-to-pay in choice models. Quantitative Marketing and Economics 5(3): 313-33I.

Sorensen J, Lucas E. 20I4. Top Io Things you Need to Know about Ancillary Revenues and Airlines. Ancillary Revenue Report Series for 2014. www.ideaworkscompany.com [I5 April 20I4].

Soyez K. 2012. How national cultural values affect pro-environmental consumer behavior. International Marketing Review 29(6): 623-646.

Stern PC. I992. Psychological dimensions of global environmental change. Annual Review of Psychology 43(I): 269-302.

Tabi A, Hille SL, Wüstenhagen R. 20I4. What makes people seal the green power deal? - customer segmentation based on choice experiment in Germany. Ecological Economics 107: 206-215.

Thompson DW, Anderson RC, Hansen EN, Kahle LR. 20IO. Green segmentation and environmental certification: insights from forest products. Business Strategy and the Environment 19(5): 319-334.

Thøgersen J. 1999. Spillover processes in the development of a sustainable consumption pattern. Journal of Economic Psychology 20(I): 53-8I.

Van Birgelen M, Semeijn J, Behrens P. 20Ir. Explaining pro-environment consumer behavior in air travel. Journal of Air Transport Management I7(2): I25-I28.

Vespermann J, Wittmer A. 20Ir. Financial, ecological and managerial impacts of emission trading schemes: the case of Lufthansa. Business Strategy and the Environment 20(3): I74-I9I.

Wegelin L, Wittmer A. 20I3. Influence of airlines' environmental activities on passengers. Journal of Air Transport Studies 3(2): 73-99.

Wittmer A, Rowley E. 20I4. Customer value of purchasable supplementary services: the case of a European full network carrier's economy class. Journal of Air Transport Management 34: 17-23. 